\title{
Immunological study of pulmonary aspergilloma
}

\author{
R A M I R O A VIL A \\ From the Department of Diseases of the Chest, Lisbon University Hospital, Portugal
}

\begin{abstract}
The various phases of pulmonary aspergilloma, as described by Pimentel, are discussed and the results of an investigation of possible cases of this disease in patients whose condition made its presence likely are presented. A systematic search for Aspergillus precipitins in the sera of 136 patients was undertaken with $\boldsymbol{A}$. fumigatus antigens. By this method two cases of pulmonary aspergilloma were diagnosed and later confirmed at operation. In a third patient the immunological diagnosis was negative but an aspergilloma was found at operation. This finding is discussed and a possible hypothesis is suggested. A pathological study of the surgical specimens is desirable to explain the false-negative Aspergillus precipitin reactions reported by various authors.
\end{abstract}

Due to the high incidence of pulmonary aspergilloma in Portugal in recent years we have tried to find a method of diagnosing the condition in those patients in whom either the clinical picture (haemoptyses and pulmonary suppuration) or potentially favouring factors (long-term antibiotic or steroid therapy, chronic bronchopulmonary disease, etc.) make its presence likely.

Aspergilloma passes through a series of phases which influence the clinical picture: we describe them here as they have an important bearing on the subject of this paper.

Although Monod, Pesle, and Meyer (1957) recognized two distinct stages in the course of pulmonary aspergilloma-one with live fungus and one with dead-it was Pimentel who showed in his numerous publications (Pimentel, 1964, 1965, 1966; Villar, Pimentel, and Freitas e Costa, 1962) that the fungus grows and dies continuously, this growth and death being partially regulated by the conditions existing in the cavity that contains the fungus (infection, active tuberculosis, etc.). In this continuous process live fungus predominates at times in the fungus ball, but at others dead fungus is more plentiful.

Once the fungus dies it undergoes regressive changes in its structure, leading to softening, fragmentation, and focal calcification. This calcification may remain focal in one or more places, may spread over a larger localized area, or may involve the greater part of the fungal mass.

\section{CLINICAL STAGES}

Mostly due to this life cycle of the fungus, five clinical or morphological stages can be defined in the course of pulmonary aspergilloma.

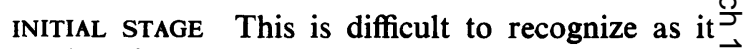
rarely gives clinical symptoms or radiological $\vec{\varnothing}$ signs. Due to the rapid growth of the fungus, it $\infty$ quickly reaches the stage of a fully developed aspergilloma. The diagnosis in this stage is exclu- $\frac{\varrho}{3}$ sively pathological and based on the finding of mycelium within a cavity either in large masses or in a thin layer covering part of its inner wall. $\stackrel{\circ}{\mathbb{Q}}$ This mycelium is always made up of viable fungus.

FULLY DEVELOPED STAGE In this stage the fungus is already growing and dying and so both live $\vec{\circ}$ and dead fungus make up the mycetoma. The cavity containing the fungus generally has a thick,, fibrous wall, but sometimes it may be of the 3 . bullous type. The different staining characteristics of the fungus, its loss of texture, fragmentation, $\frac{0}{3}$ softening, liquefaction, and the deposition of calcium salts enable one to distinguish the dead ${ }^{\circ}$ from the live fungus (Pimentel, 1959), there being a $\frac{D}{O}$ predominance of one or the other in the fungus ball.

From a clinical point of view it has been $N$ generally stated that haemoptyses are the most N frequent manifestation of live fungus, whereas $\omega$ pulmonary suppuration is that of the dead fungus. However, Pimentel (1965), in 72 patients with live aspergilloma, found 63 with repeated haemoptyses $\stackrel{\oplus}{\hookrightarrow}$ and nine with signs of pulmonary suppuration, 7 while 19 patients with dead aspergilloma all had ${ }^{\circ}$ haemoptyses. Therefore he concluded that the $\mathbb{\mathbb { Q }}$ symptoms probably depend more on the relation $\frac{}{1}$ between the fungal mass and the cavity wall than $\frac{\varrho}{\sigma}$ on the vitality of the fungus. 
CALCIFIED ASPERGILLOMA In this phase the fungus ball is turned into a completely calcified concretion within which the hyphae can be recognized by staining with methenamine-silver after decalcification. This phase has been infrequently recognized in Portugal (two cases), probably due to the fact that in the majority of cases the 'dead' fungus liquefies and is eliminated with the sputum. It is only in those cases where the dead and calcified fungus is retained within the cavity that a calcified aspergilloma forms. Between dead fungus with focal calcifications and calcified aspergilloma all transitions can be found. Clinically, repeated haemoptyses dominate the picture in this stage.

RESIDUAL STAGES These may be seen in two forms.

Abscesses containing fragments of mycelium Clinically, these patients have a chronic lung abscess, and it is only by a careful search for the remains of the aspergillar hyphae in the cavity that this form can be diagnosed. The fungus is generally not viable, but the methenamine-silver technique is very helpful in identifying it.

Broncholiths and cavernoliths These can be found in bronchial dilatations or pulmonary cavities as tiny concretions either free or incorporated within the granulation tissue of the cavity wall. After decalcification and staining by the methenamine-silver technique they show small masses of septate hyphae as are found in other aspergillomas. One could say that these are a calcified form of the other residual stage.

Patients with this form of aspergilloma are generally considered to have a cavitary form of tuberculosis with negative sputum and frequent bouts of haemoptysis.

ABORTIVE FORM This form of aspergilloma is pathologically very similar to the residual form, differing only in not being preceded by the fully developed stage. This seems to be the result of a frustrated attempt by the fungus to develop and grow within the cavity and generally has no clinical expression.

\section{MATERIAL AND METHODS}

With the idea of finding possible cases of pulmonary aspergilloma in any of its stages, although not presenting the classical clinical or radiological features, we tested the sera of 136 patients with chronic lung disease, subjected to long-term anti- biotic or steroid therapy, for Aspergillus fumigatus precipitins.

The diagnosis was confirmed by pathological examination of the resected specimens, done in all cases by Pimentel, who is highly experienced in this matter.

The clinical diagnoses for our 136 patients are shown in the Table.

\section{T A B L E}

\begin{tabular}{|c|c|c|c|c|c|}
\hline \multicolumn{5}{|c|}{ Diagnosis } & \multirow{3}{*}{$\begin{array}{c}\text { No. } \\
63 \\
25 \\
16\end{array}$} \\
\hline \multicolumn{5}{|c|}{$\begin{array}{l}\text { Chronic cavitary tuberculosis with haemoptysis } \\
\text { Chronic cavitary tuberculosis without haemoptysis.. }\end{array}$} & \\
\hline Unclassified pu & monary suppurat & .. & $\cdots$ & & \\
\hline Bronchiectasis & . & 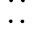 & $\cdots$ & & 11 \\
\hline Pleurisy .. & . & .. & . & & 7 \\
\hline Lung tumour & $\therefore$ & .. & $\therefore$ & & 7 \\
\hline Echinococcus & yst of the lung & $\cdots$ & 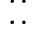 & & 7 \\
\hline
\end{tabular}

As antigens we used four extracts of $A$. fumigatus cultures, two kindly sent us by Professor J. Pepys of London and the other two by the Pasteur Institute in Paris. At first.we used the microtechnique of double diffusion in agar, described by Hartmann and Toilliez (1957), and the macrotechnique of Ouchterlony (1949). Later we did immunoelectrophoresis according to Scheidegger (1955). All these techniques had to be adapted to our material.

\section{RESULTS}

Pathological study of the resected specimens showed that, in this group of 136 patients, three had aspergillomas. However, $A$. fumigatus precipitins could be demonstrated in only two of these.

These case reports follow.

CASE 1 J.P. was a 52-year-old mechanic. Approximately one and a half years before admission to hospital he had a cough" and blood-streaked sputum, and had lost weight. Cough, purulent sputum, dyspnoea, and a further loss of weight had been noted in the last two months, and crepitations were heard in the base of the right lung. Chest radiographs showed a cavity in the base of the right lung, partially filled by a homogeneous mass with areas of higher density suggesting calcification (Fig. 1). All tests for A. fumigatus precipitins in the patient's serum, using four different antigens and the microtechnique of double diffusion in agar, were persistently negative. However, using the immunoelectrophoretic technique, the test proved positive (Fig. 2).

After pneumonectomy, the resected specimen showed endobronchiectatic aspergilloma with suppuration. The greater part of the fungus constituted a 


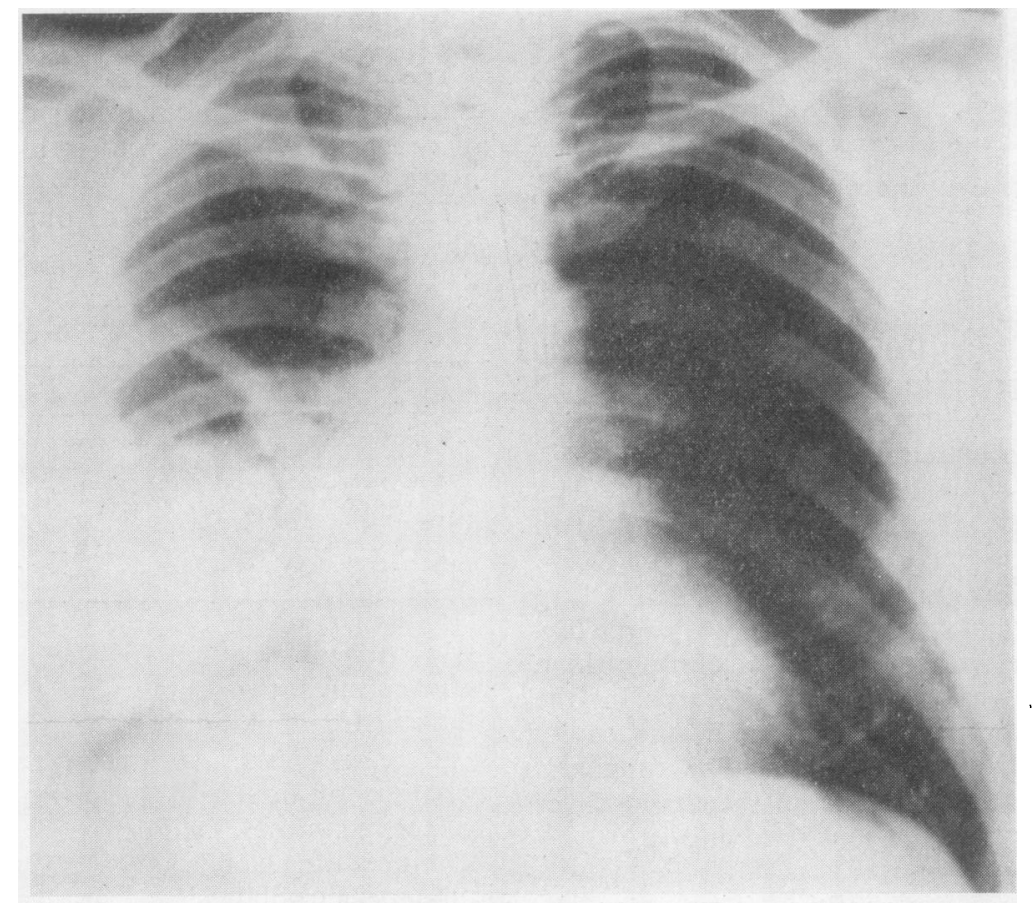

FIG. 1. Case 1. Chest radiograph.

large mycelial sequestrum with extensive calcifications. In some areas, however, hyphae with the characteristics of live fungus could be seen (Fig. 3).

Comment This patient, with a history of pulmonary suppuration, had $A$. fumigatus precipitins in circulation, although these were detected only by the immunoelectrophoretic technique. Unfortunately, we did not use Ouchterlony's technique in this case (Ouchterlony, 1949).

Pathological examination of the specimen confirmed the immunological diagnosis, as it showed a calcified aspergilloma with some live hyphae.

CASE 2 C. F. R. was a 46-year-old housewife. Cough and progressive dyspnoea began two months before hospitalization and led to admission through the emergency ward. When she was 18 years old this patient had had a haemoptysis for which an artificial pneumothorax was done during her eight months in hospital. There had been no subsequent trouble.

On admission a right pleural effusion was found, but on repeated pleural taps no tubercle bacilli or other pathogenic bacteria were found in the fluid, and repeated cultures for fungi grew only a contaminant (Pullularia). Chest radiographs, after numerous pleural taps, showed a collapsed right lung, pneumothorax, and a large mass occupying approximately one-third of the pleural cavity (Fig. 4): the mass was particularly well demonstrated by tomography. On testing this patient's serum against the antigens of? A. fumigatus, by both double diffusion and immunoelectrophoresis (Fig. 5), precipitins were clearly
demonstrated.

A right pleural decortication was carried out. Theo resected specimen showed a pleural aspergilloma with numerous calcifications among hyphae having the appearance of live fungus (Fig. 6).

Comment This patient with a pleural effusion had $A$. fumigatus precipitins in her serum? The resected specimen confirmed the diagnosis $\frac{}{7}$ of aspergilloma, although aspergillomas have rarely been reported in the pleura in Portugal $N$ Besides live fungi extensive intrapleural calcifica tions were found.

CASE 3 M. L., a 56-year-old male rural workero complained of a dry cough since childhood and various bouts of pulmonary suppuration in the las $\bar{D}$ few years.

Foul, purulent, sometimes blood-streaked sputum and progressive breathlessness had appeared one an $\delta$ a half years previously. Weakness and a loss of $8 \mathrm{~kg}$ in weight took place during the previous eigh? months, and four months previously the patient rar a temperature of $101-103^{\circ} \mathrm{F} .\left(38-39^{\circ} \mathrm{C}.\right)$. Crepitag tions were heard in the upper third of the left chest 


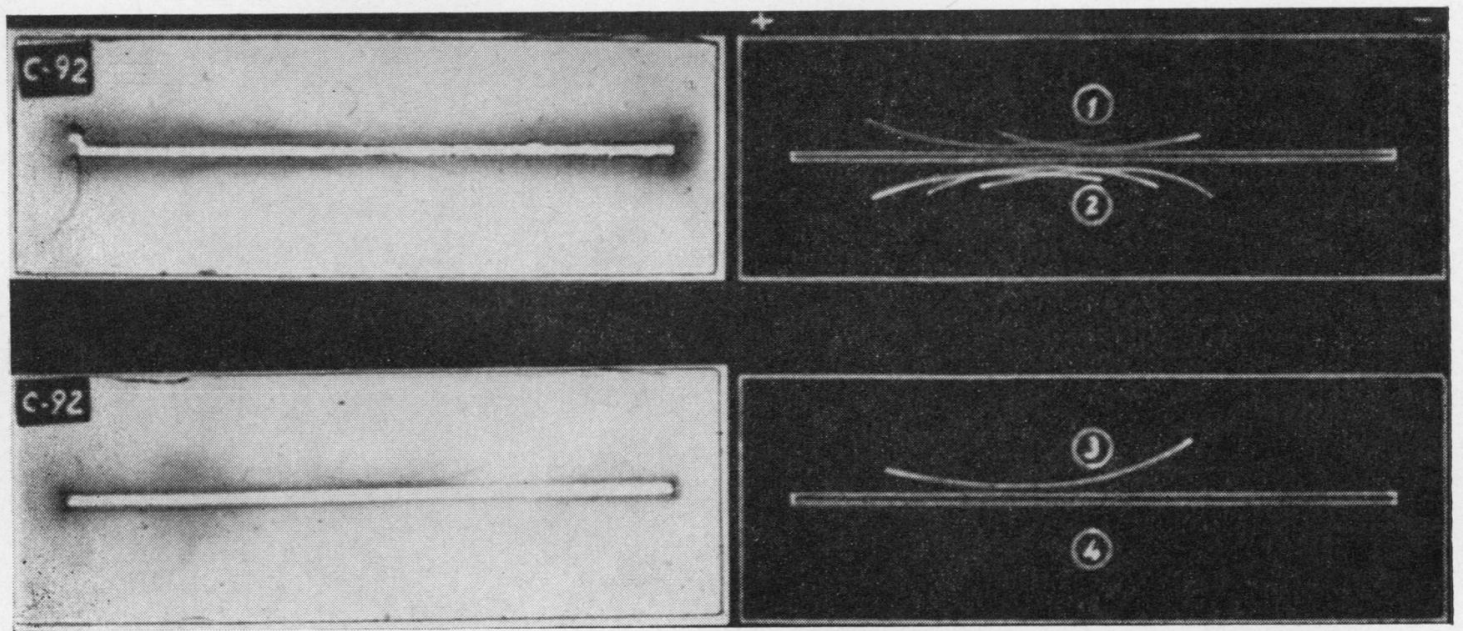

FIG. 2. Case 1. Immunoelectrophoresis of patient's serum against the four antigens.

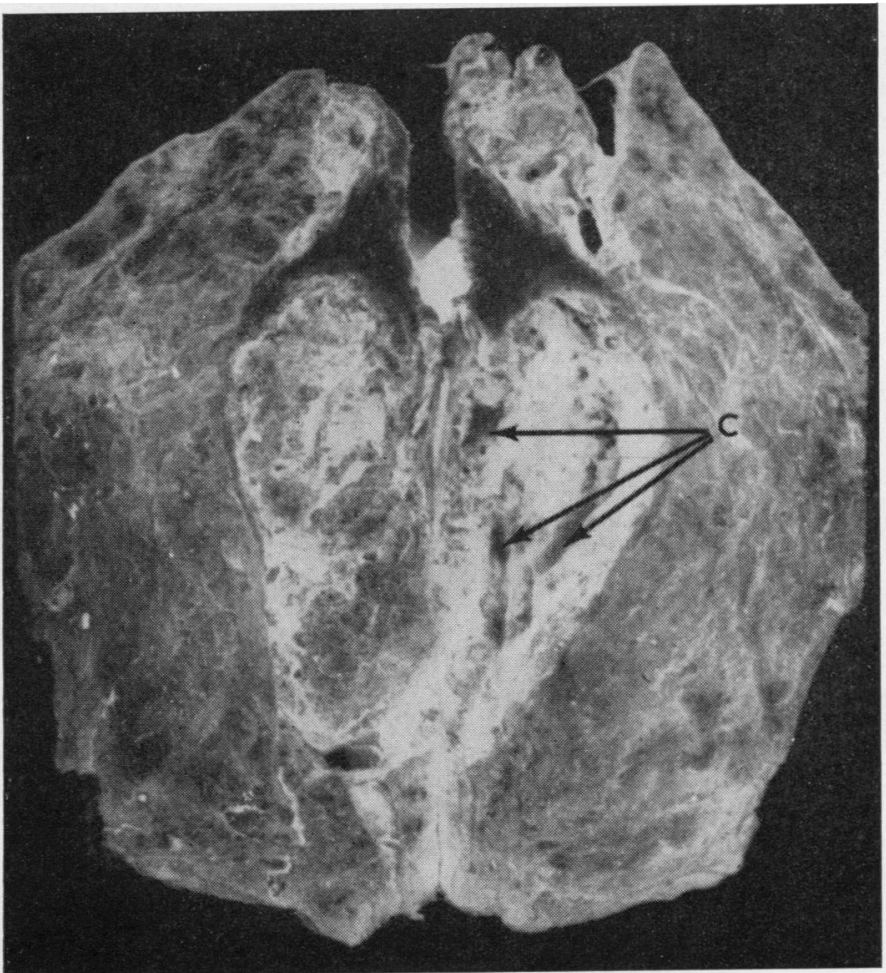

FIG. 3. Case 1. Macroscopic appearance of the aspergilloma. Note deposition of calcium $(C)$ in fungal mass. 


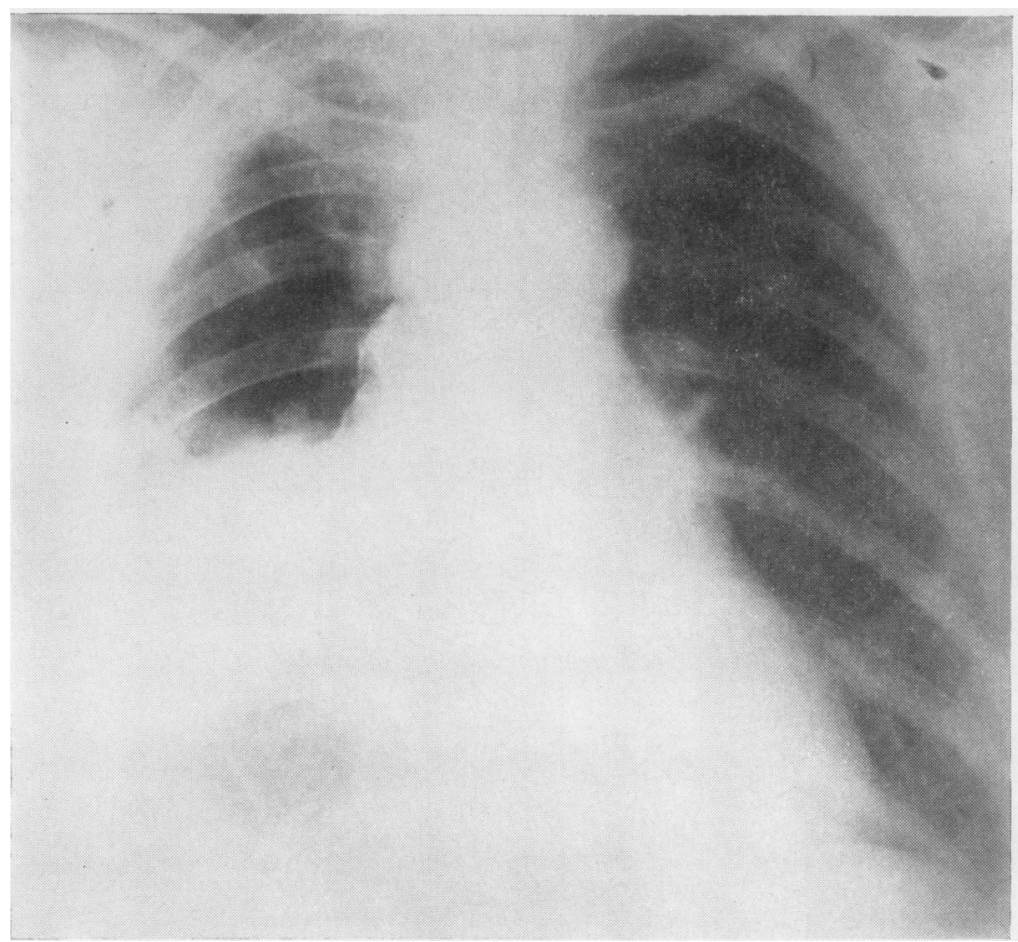

FIG. 4. Case 2. Chest radiograph.

FIG. 5. Case 2. Immunoelectrophoresis of patient's serum against the four antigens. 


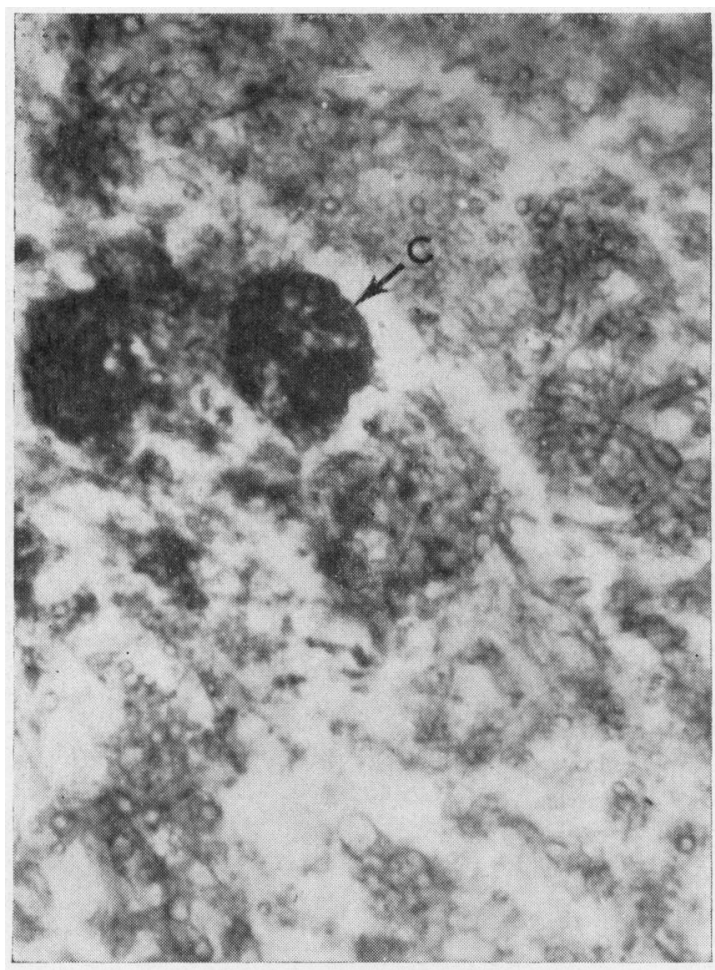

FIG. 6. Case 3. Microscopical appearance of the aspergilloma. Note deposition of calcium $(C)$ in fungal mass.
A chest radiograph showed a zone of uneven density in the periphery of the left upper lobe. Tomography showed a thick-walled cavity containing a round homogeneous mass with an 'air crescent' above it (Fig. 7), and at bronchography this cavity was entered by the contrast medium and the endocavitary mass was displaced by it (Fig. 8). Repeated examination of the sputum was negative for bacteria, but mycological techniques showed Penicillium sp., and Candida albicans. No Aspergillus was grown.

The search for circulating antibodies against $A$. fumigatus in the patient's serum, using four different antigens, was persistently negative by both microtechnique and macro-technique of double diffusion in agar and immunoelectrophoresis. The clinical diagnosis was pulmonary aspergilloma, and a left upper lobectomy was done. Examination of the resected lobe showed a bronchiectatic cavity, with signs of suppuration, containing some small residues of aspergillar mycelium - $a$ form of residual aspergilloma (Fig. 9).

Comment This is a case of residual aspergilloma which it was not possible to diagnose by the demonstration of $A$. fumigatus precipitins, although we used antigens with which we had previously obtained $100 \%$ positive results.

\section{DISCUSSION}

Although in most of our cases we also used Ouchterlony's (1949) technique, we systematically

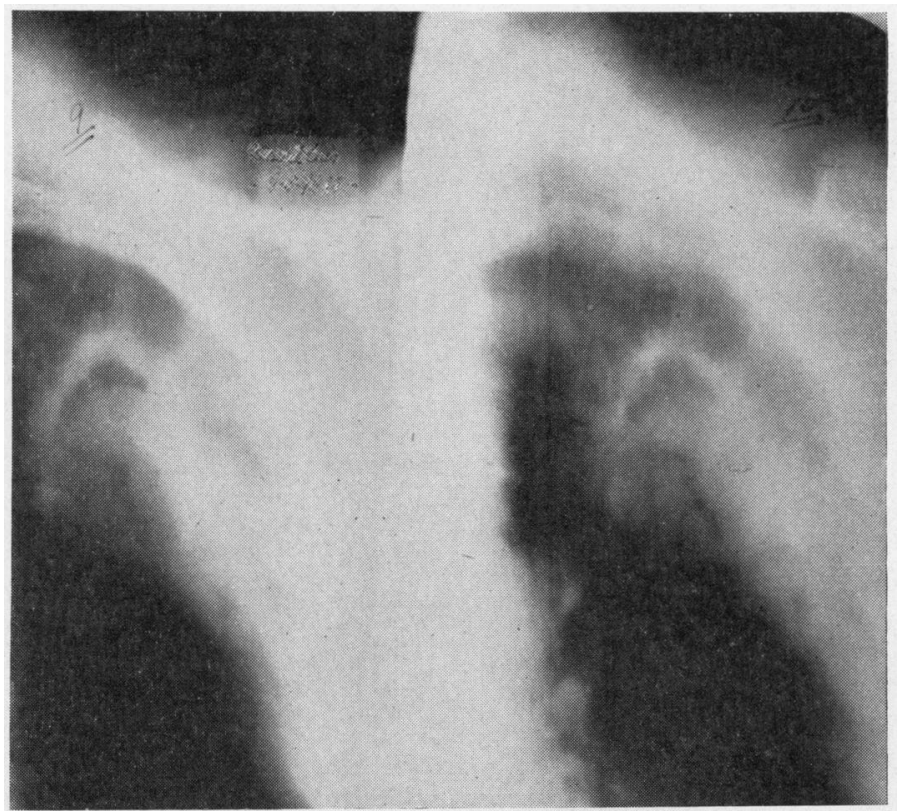

FIG. 7. Case 3. Tomography at $9 \mathrm{~cm}$. (left) and $10 \mathrm{~cm}$. (right). 


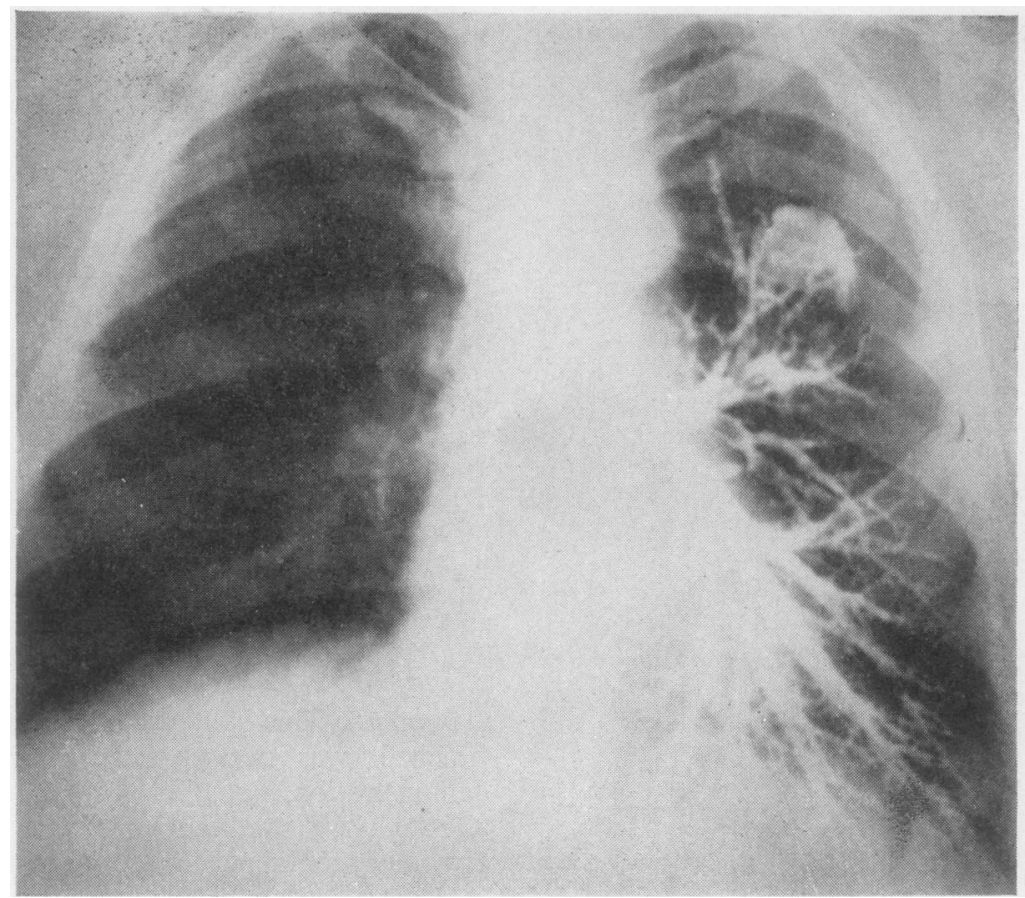

FIG. 8. Case 3. Bronchography.

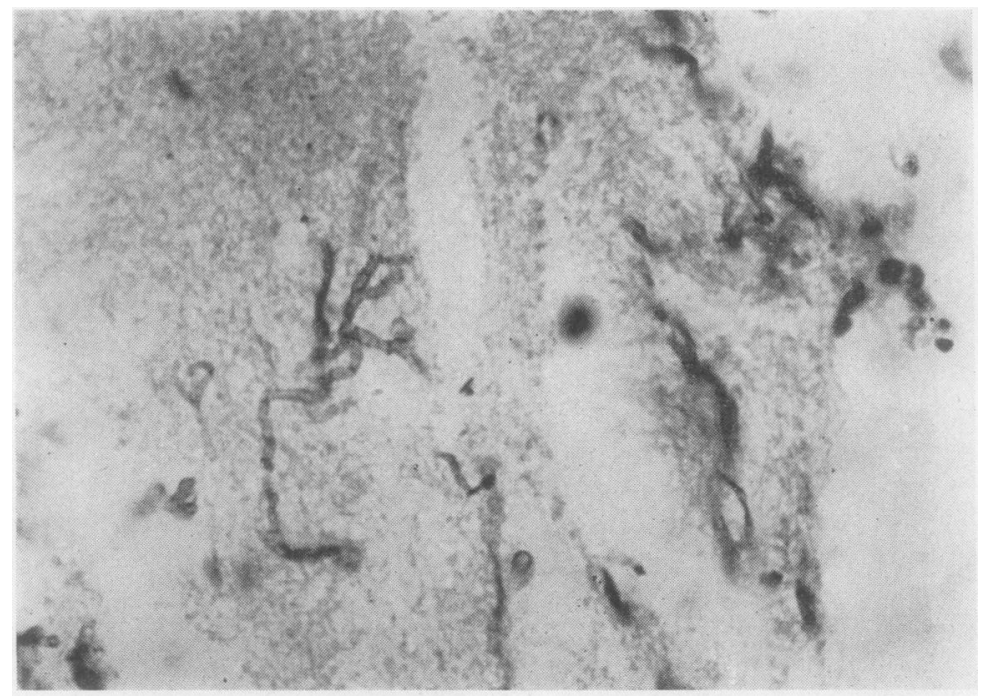

FIG. 9. Case 3. Microscopical appearance of the residual form of aspergilloma after decalcification and staining by the methenamine-silver technique. Along with necrotic tissue, septate hyphae of Aspergillus are clearly seen. 
employed two techniques for the immunological diagnosis of pulmonary aspergilloma: the microtechnique of double diffusion in agar, and immunoelectrophoresis. We preferred the microtechnique to Ouchterlony's method because this technique has proved to be particularly simple, rapid, and economical. Contrary to Ouchterlony's macro-technique, in which the results are sometimes not obtained until 10 to 14 days later, the micro method gives reliable results in 48 hours. The quantities of antigen and serum used in the latter technique are minimal, which makes it more economical. In none of our cases was Ouchterlony's technique positive when our method was negative. Unfortunately, case 1 was one of the few in which we did not use Oucherlony's technique as well, but the positive immunoelectrophoresis left us in no doubt as to the diagnosis.

Only three cases of aspergilloma were found in the 136 patients studied, two of which were diagnosed pre-operatively by immunological methods.

It was impossible to identify the genus of the Aspergillus in case 3 as it was a residual aspergilloma with dead, non-viable fungus, but the typical septate hyphae were clearly demonstrated by the methenamine-silver stain, the possibility of the fungus ball being due to another fungus, as has been described (Louria, Lieberman, Collins, and Blevins, 1966; Wilhite and Cole, 1966; Smith, 1960 ; Stoeckel and Ermer, 1960; Perruchio, Bruel, Lagarde, and Delpy, 1959), being eliminated.

Voisin, Biguet, Tran van Ky, Schouller, Sergeant, and Gernez-Rieux (1964), studying 90 chronic tuberculosis patients in a manner similar to ours, found eight cases. These authors, however, attribute this high incidence to their choice of patients and to the duration of the primary disease.

Longbottom, Pepys, and Clive (1964) report three cases whose sera did not react to extracts of $A$. fumigatus but did so to antigens prepared from cultures of $A$. niger, $A$. flavus, and $A$. nidulans. Although in 70 cases of pulmonary aspergilloma in which the cavity contents were cultured Pimentel (1967) consistently found $A$. fumigatus, other species of Aspergillus had been cultivated from the sputum of some of the patients, and we have to admit that case $3 \mathrm{might}$ be similar to one of those described by Longbottom et al. (1964).

However, another hypothesis may be suggested. In 57 patients Longbottom and Pepys (1964) failed to demonstrate precipitins in only one case.

Gernez-Rieux, Biguet, Voisin, Capron, Bal- gaires, and Tran van Ky (1963) could not demonstrate precipitating antibodies by electrophoresis in six patients with radiologically characteristic signs of aspergilloma. Three of the patients had thoracotomies, and in two intracavitary caseous remains were found which simulated fungal masses. In the third case an intracavitary aspergilloma was found but the species of Aspergillus could not be determined. During the discussion of a paper by Voisin et al. (1964), Monod (1964) stated that he also could not demonstrate precipitins in a patient with an aspergilloma confirmed by operation. Drouhet, Segretain, Pesle, and Bidet (1963a and b) obtained weak or negative immunological responses in two patients.

We must consider the presence of $A$. fumigatus precipitins in patients in whom pulmonary aspergilloma due to $\boldsymbol{A}$. fumigatus had been surgically removed. Voisin et al. (1964) conclude that six weeks to three months after surgical removal of the aspergilloma the serum precipitins disappear and, if they do not, this means that foci containing Aspergillus remain in the body. However, Monod (1963) continued to get positive though weak reactions in three cases 5,7 , and 13 months after surgical removal.

On the other hand, Longbottom and Pepys (1964) studied eight patients after operation and found weak reactions in five. Two of these patients had associated asthma and pulmonary eosinophilia, which could explain the persistence of the positive reaction. However, these authors do not mention the time interval between operation and post-operative testing.

In two patients operated on for aspergilloma due to $A$. fumigatus we found positive immunological reactions one month after operation, but it was not possible to follow up these patients any further. Four other patients who had not been tested pre-operatively were studied respectively 24 , 20,17 , and 11 months after removal of the aspergilloma and in none of them could A. fumigatus precipitins be demonstrated. We therefore confirm the opinion of other authors and conclude that surgical removal of an aspergilloma leads to a progressive decrease in circulating antibodies and finally to their complete disappearance from the patient's serum.

As we have shown in our opening observations, in some stages aspergillomas may be totally devoid of live fungus, this being present as a calcified concretion, as endocavitary residues, or as broncholiths and cavernoliths. We think that, as the patient can live with one of these forms for many years, the lack of live fungus could lead to 
a loss of antigenic stimulus to the body leading to the disappearance of circulating antibodies from the serum, in the same way that they disappear after surgical removal of the aspergilloma. Cases 1 and 2, although cases of calcified aspergilloma, still retained some live fungal elements which could act as antigenic stimuli, thus justifying the finding of $A$. fumigatus precipitins in the circulation. On the other hand, case 3 , being a residual aspergilloma, could, in our opinion, have no circulating precipitins for the same reason that these are not found in those patients from whom aspergillomas have been surgically removed.

We should like to suggest that, in all cases of pulmonary aspergilloma in which $A$. fumigatus precipitins are not found, a careful pathological study should be undertaken not only to determine the species of Aspergillus involved, but especially to determine what stage the aspergilloma is in, as we feel that the hypothesis we have presented may be an explanation for some of the false negative results of the precipitin tests used for the diagnosis of pulmonary aspergilloma.

Any search for pulmonary aspergilloma undertaken by immunological methods would have to bear these considerations in mind and admit the possibility of cases containing only dead fungus being missed.

\section{REFERENCES}

Drouhet, E., Segretain, G., Pesle, G., and Bidet, L. (1963a). Valeur de la recherche des précipitines sériques en milieu gélifié pour le diagnostic des aspergilloses broncho-pulmonaires. J. franc. Méd. Chir. thor., 17, 655 .

(1963b). Étude des précipitines sériques en milieu gélosé pour le diagnostic des aspergilloses bronchopulmonaires. Ann. Inst. Pasteur, 105, 597. Gernez-Rieux, Ch., Biguet, J., Voisin, C., Capron, A., Balgaires, E.,
and Tran Van Ky, P. (1963). aspergillomes broncho-pulmonaires par immuno-électrophorèse. J. frans. Méd. Chir. thor., 17, 663.

Hartmann, L., and Toilliez, M. (1957). Micro-méthode d'étude en gélose de la réaction antigène-anticorps. Rev. franc. Étud. clin. biol., 2, 197.

Longbottom, J. L., and Pepys, J. (1964). Pulmonary aspergillosis: Diagnostic and immunological significance of antigens and $C$ substance in Aspergillus fumigatus. J. Path. Bact., 88, 141. aspergillus pulmonary mycetoma. Lancet, 1, 588 . ouria, B. D., Lieberman, P. H., Collins, H. S., and Blevins, A. (1966). Pulmonary mycetoma due to Allescheria boydii. Arch. intern. Med., 117, 748 .

Monod, O. (1963). Discussion of the paper by Drouhet, [E., et al., in J. franc. Méd. Chir. thor., 17, 661 .

(1964). Discussion of the paper by Voisin et al., in Rev. Tuberc. N (Paris), 28, 1311.

- Pesle, G., and Meyer, A. (1957). L'aspergillome bronchectasiant. Sem. Hôp. Paris, 33, 3588.

Ouchterlony, O. (1949). Antigen-antibody reactions in gels. Acta path. A microbiol. Scand., 26, 507.

Perruchio, P., Bruel, R., Lagarde, C., and Delpy, J. (1959). Le torulome bronchectasiant. Une nouvelle forme clinique de la torulose respiratoire. Presse med., 67, 387.

Pimentel, J. Cortez (1959). Novos aspectos morfológicos do “Aspergiloma" pulmonar. Seus prováveis estádios iniciais e residuais. Gaz. méd. port., 12, 195.

- (1964). Calcificações na aspergilose pulmonar tumoriforme (Aspergiloma pulmonar). Aspectos anátomo-clínicos: Dificuldades de diagnóstico com a tuberculose. Ibid., 17, 252.

(1965). Alguns aspectos anátomo-clínicos das aspergiloses pulmonares em Portugal. J. Med. (Porto), 56, 881

_- (1966). Pulmonary calcification in the tumour-like form of pulmonary aspergillosis: Pulmonary aspergilloma. Amer. Rev. resp. Dis., 94, 208. - (1967). Personal communication.

Scheidegger, J. J. (1955). Une micro-méthode de l'immuno-electrophorése. Int. Arch. Allergy, 7, 103.

Smith, A. (1960). Aberrant forms of "Coccidioides immitis" in a Coccidioidoma. Amer. J. clin. Path., 34, 477.

Stoeckel, H., and Ermer, C. (1960). Ein Fall von Monosporum Mycetom der Lung. Beitr. Klin. Tuberk., 122, 30.

Villar, T. G., Pimentel, J. C., and Freitas e Costa, M. (1962). The tumour-like forms of aspergillosis of the lung (pulmonary aspergilloma). A review of 5 new cases and a review of the Portuguese literature. Thorax, 17, 22.

Voisin, C., Biguet, J., Tran Van Ky, P., Schouller, A., Sergeant, Y. H., and Gernez-Rieux, Ch. (1964). Aspergilloses latentes et tuberculose pulmonaire chronique. Rev. Tuberc., 12, 1311.

Wilhite, J. L., and Cole, F. H. (1966). Invasion of pulmonary cavities by Nocardia asteroides: Report of 5 cases. Amer. Surgn, 32, 107 . 